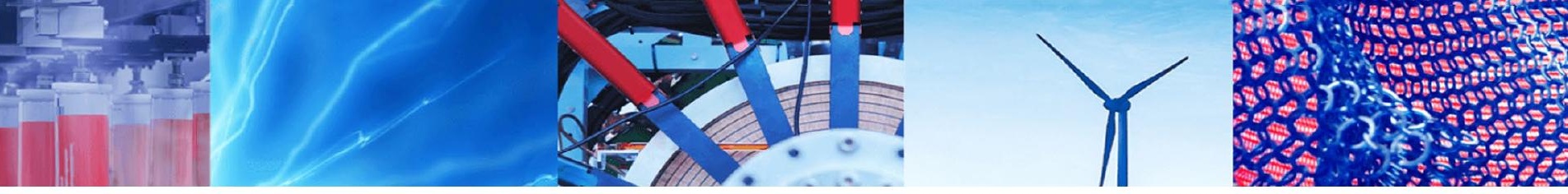

Review Paper

\title{
A brief review on cryogenics in machining process
}

\author{
Divya Zindani ${ }^{1} \cdot$ Kaushik Kumar $^{2}$ (i)
}

Received: 22 December 2019 / Accepted: 12 May 2020 / Published online: 21 May 2020

(c) Springer Nature Switzerland AG 2020

\begin{abstract}
Machining processes aided by cryogenics, and therefore known as cryogenic-assisted machining, are one of the emerging sustainable means of machining superior quality products. The major objective of this work is to brief the readers with the advancements and developments taking place during last few decades in this emerging area of machining technology. The work incepts with an introduction section encompassing delineation of the conceptual framework of cryogenicassisted machining processes, i.e., the definition and scope of the processes. Subsequently, the readers are illuminated with the thermal aspects of the cryogenic-assisted machining processes. Main applications of the cryogenic-assisted machining processes are discussed next. Consequently, economic aspects have been delineated in the penultimate section of the present work. The sustainability issues associated with the cryogenic-assisted machining have also been discussed in the present work. The work finally terminates with brief concluding remarks encompassing future perspectives.
\end{abstract}

Keywords Cryogenics · Sustainable machining · Product quality

\section{Introduction}

The word "Kryos" is a Greek word that means cold. Thus, cryogenics means working in the environment of low temperature. The first cryogenic laboratory was built by Heike Kamerlingh Onnes in the year 1882. The lab was set up at University of Leiden (Netherlands) which became one of the leading cryogenic center and remained to be so for a period of over five decades. Inconsistencies have been reported for identification of the beginning temperature of cryogenics. In accordance with most research and standard organizations, cryogenics begins at or below $123 \mathrm{~K}$. National Institute of Standards and Technology has considered the temperature to be lower than $93.15 \mathrm{~K}$ as beginning point for cryogenics. Temperatures below $120 \mathrm{~K}$ have been regarded as cryogenics temperature by the Cryogenic Society of America. Various researchers consider temperatures below $0{ }^{\circ} \mathrm{C}$ as the cryogenic temperature [1-6].
Reitz [7] in the year 1919 reported the use of liquefied gases as cooling agent for carrying out the machining operations. Carbon dioxide gas was used by Reitz as a coolant in machining operations. The concept of cryogenic hardening was developed by scientists when they discovered that a greater wear resistance was exhibited by metals frozen to low temperatures. CryoTech Company of USA was the first to introduce the concept of cryogenic machining in the year 1966. Increase in metal tool life was reported by carrying out the machining process under cryogenic environment. Subsequently, in the year 1976, ASHARE [8] was credited to establishing of guidelines for applications in the domain of cryogenic applications.

With the gradual acceptance of application of cryogenics, Uehara and Kumagai [9] introduced cryogenic machining in the year 1968. Traditional oils was replaced as a coolant with the liquid gases such as helium, carbon dioxide, and nitrogen. Alteration in properties of workpiece, cutting tool, and the quantum of heat dissipated in the cutting zone has been reported by various researchers

Kaushik Kumar, kkumar@bitmesra.ac.in | 'Department of Mechanical Engineering, National Institute of Technology Silchar, Silchar 788010, India. ${ }^{2}$ Department of Mechanical Engineering, Birla Institute of Technology Mesra, Ranchi, India. 
investigating cryogenic machining [10-12]. The potentiality of cryogenic machining to obtain surfaces with lesser damaged surfaces and with lower residual thermal stresses was henceforth proved after the investigations.

One of the well-known coolant for machining operation, i.e., water, has been evidenced for machining processes way back in sixteenth century [13]. With time, cutting fluids based on oil and water cutting fluids gained popularity in the twentieth century and have been used widely in machining of steel alloys. The main objective of employing cutting fluids is to enhance the rate of heat transfer from the cutting area and therefore to diminish the thermal stresses as well as the mechanism of chemical wear. In totality, the employability of cutting fluids improves the overall quality of the product [14-18]. However, the use of cutting fluids can result in human health complications such as respiratory diseases, dermatitis, and cancers [19-21].

The machining operations were made sustainable with the advent of coated cutting tools in the 1970s. Such machining processes were referred to as dry machining. However, due to the lack of availability of suitable coating materials, dry machining processes could not get the desired popularity. The applicability of the near dry machining processes was evidenced in the 1990s and with further progress became a more suitable sustainable machining alternative to dry machining. Employability of near dry machining processes resulted in reduction of amount of lubricants or the cutting fluids employed in carrying out various machining processes. Enhanced machining performances in terms of power consumption, surface roughness, and tool life have been reported with the near dry machining processes. Even after such advantages, the applicability of near dry machining processes has been limited. Further, the environmental and health implications of such machining processes requires further investigations. Investigations have been reported by various researchers on some of the challenges and limitations associated with the near dry machining processes [22-24].

Cryogenic machining process is yet another emerging sustainable machining which has done away with the conventional metalworking fluids. Liquefied gases such as nitrogen and the other non-toxic, odourless, and non-hazardous liquefied gases have replaced the different metalworking fluids. Further, the requirements for maintenance as well as post-machining disposal and cleaning processes are also minimized [25-30]. Further, higher rate of material removal and hence lower consumption of energy [31, 32] has been achieved owing to the increased hardness and toughness of the cutting tool material. Lower working environment is credited to increased tool material hardness and toughness. Components obtained using from cryogenic machining have been reported to show enhanced properties such as fatigue life, wear resistance, and corrosion resistance [31-36]. The conditions under which the coolants are used dictate the performance of the machining processes. The use of aforementioned cooling fluids is, however, limited owing to the constraint associated with usage in bulk for cooling.

Cryogenic machining therefore offers dual advantage as it combines the advantages of dry machining with that of the rapid rate of cooling. The two prominently used gases, i.e., $\mathrm{CO}_{2}$ and $\mathrm{LN}_{2}$ have got different requirements for their use. Further, they also distinguish from one another in the mechanism of generation of low temperatures. Technological advancements have led to the development of different strategies to aid in lubricating the cutting zone. As for instance, $\mathrm{CO}_{2}$ and $\mathrm{LN}_{2}$ have been combined with very minute quantities of oil particulates in MQL form.

With the today's world being focussed on sustainability, the present work aims to summarize the recent aspects of cryogenic machining. With this major objective, thermal aspects related to the cryogenic-assisted machining processes have been discussed in Sect. 2 of the work. Section 3 highlights the major applications of the cryogenicassisted machining processes. In the penultimate section of the work, i.e., Sect. 4 depicts the economic aspect of the cryogenics in machining processes. Section 5 highlights the sustainability issues of the cryogenics-assisted machining processes and the work finally concludes with the concluding remarks encompassing the future perspectives.

Figure 1 depicts the top journals that have contributed to the field of cryogenic machining.

The top 10 countries to have contributed actively to the cryogenic manufacturing domain have been delineated in Fig. 2.

\section{Cryogenic machining of Al and Ti alloys}

A network of capillaries aids the penetration of cryogenic fluid at the tool-chip interface. Diffusion is another penetration mechanism through which the cryogenic fluid enters the cutting area through the primary zone of deformation. The cutting fluid aids in reduction of the temperature by reducing the energy required for cutting and also by enhancing the potential ability to extract heat from the cutting zone. Reduced fracture strain of the workpiece material has been observed for cryogenic machining of ductile materials [37]. Enhanced energy of cutting was also observed for the same. Heat extraction is proportional to the difference between temperature of the coolant and the surface temperature of the body and also to the coefficient of heat transfer. Conventional cutting fluid have temperatures of around $25^{\circ} \mathrm{C}$, whereas liquefied nitrogen gas has temperature of around $-196^{\circ} \mathrm{C}[39]$. Therefore, a total 


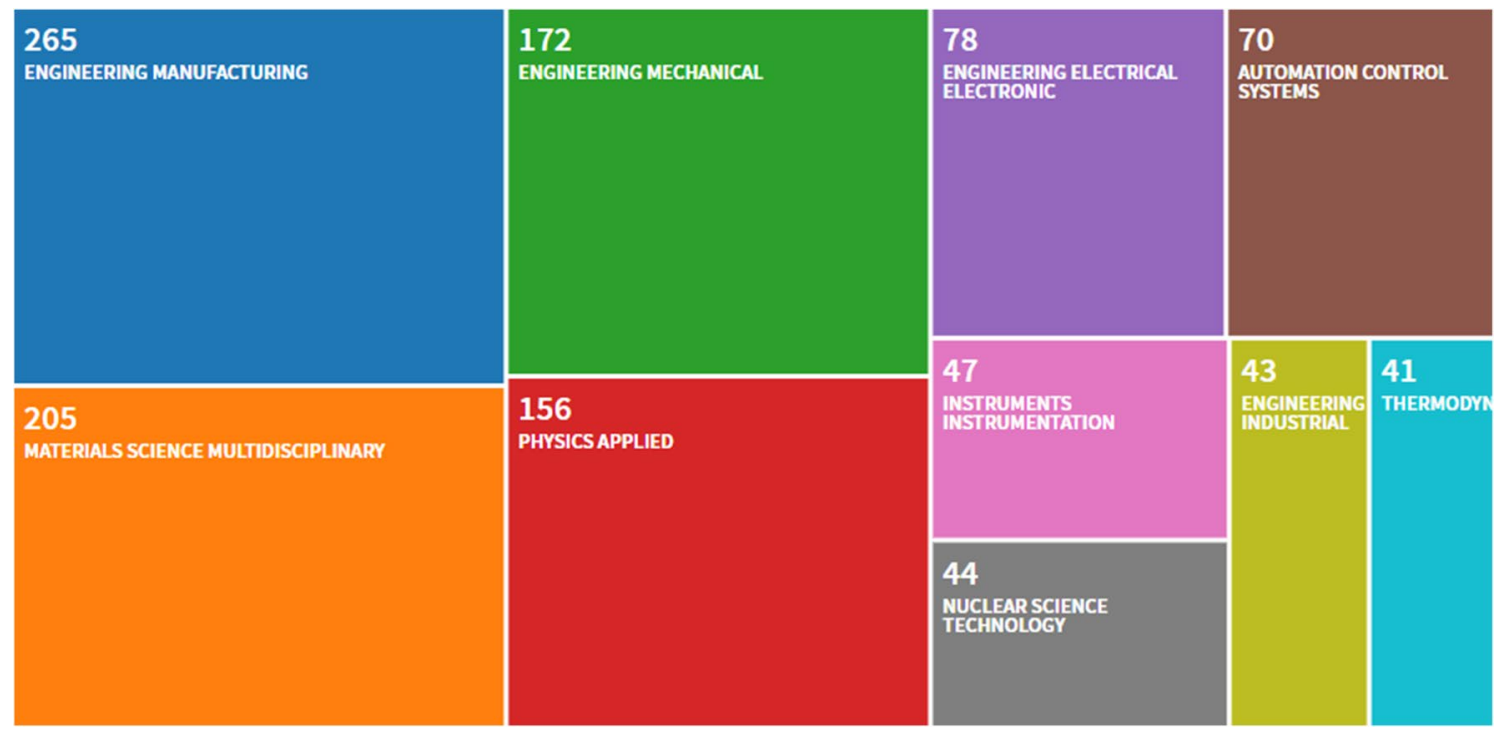

Fig. 1 The top 10 journals contributing toward the domain of cryogenic machining

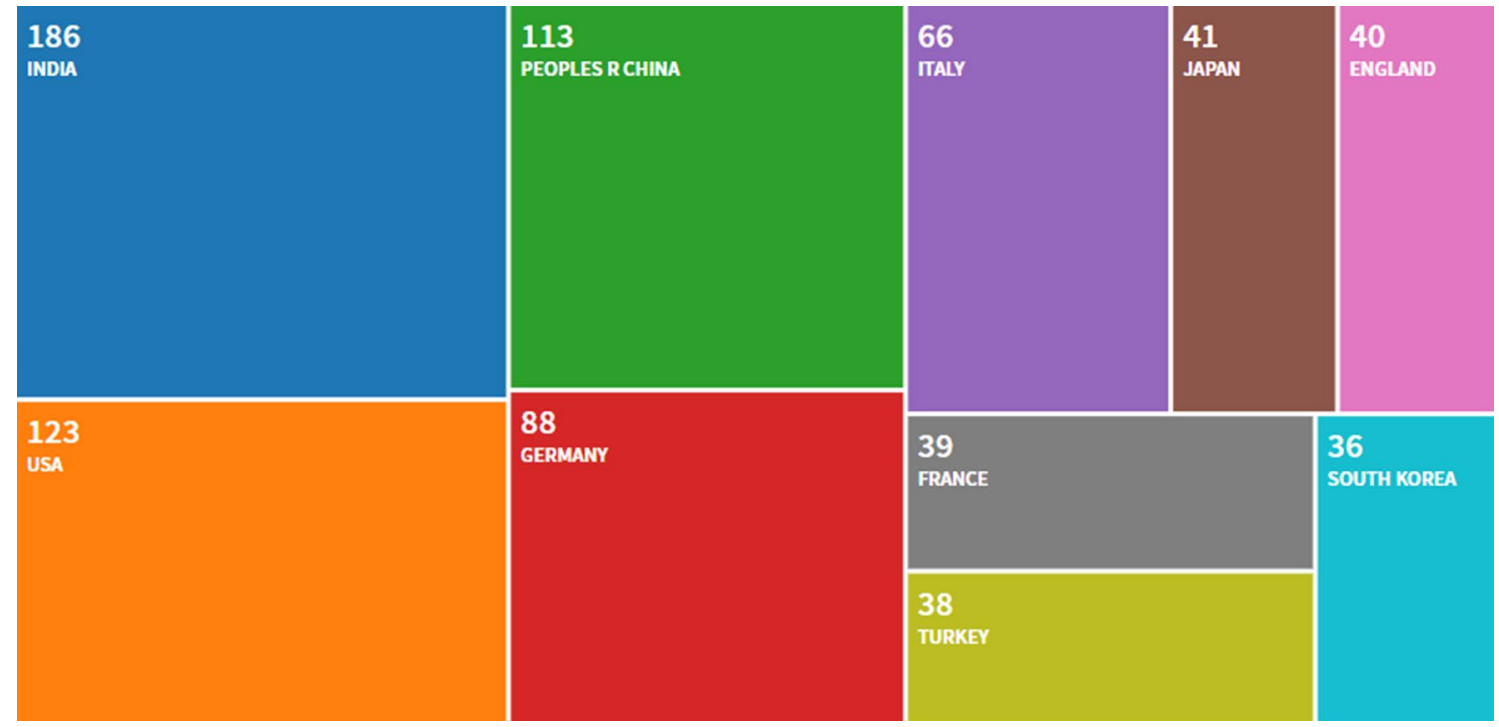

Fig. 2 The top 10 countries contributing towards the domain of cryogenic machining

advantage of $220^{\circ} \mathrm{C}$ of the liquefied nitrogen gas over the other conventional fluids. As a result of heat transfer to the cryogenic fluid, gas cushion is formed at the tool-chip interface due to the evaporation of the cryogenic coolant [38].

To control the cutting temperature, it is quintessential to control the direction and manner in which the cryogenic cutting fluid is supplied to the cutting area. The cryogenic cutting fluids are applied over the chip flowing area, zone of primary deformation arising on chip and at the two interfaces, i.e., tool flank-workpiece interface and the other at tool-chip interface. Provision is also there to direct the cutting fluid on to the tool insert [40]. Therefore the tool and the workpiece material can be cooled separately. The flow of cryogenic fluid is known as confined flow if the direction of flow is from flowing over the chip through the tool-chip interface. The free flow condition is established if the fluid flows towards the tool flank-workpiece interface or if on to the tool insert. The distinction between the type of flow aids in establishing the dynamics of fluid flow and also the heat transfer mechanism.

Under the free flow condition, three regions can well be identified, i.e., free jet region, wall jet region and stagnation region. In the wall jet region, the flow follows outward 
radial direction. Further, the boundary layer starts to develop at the stagnation point having a very prominent role in the rate of heat transfer. A structured coherent vortices develop around the impinging jet owing to the entrapment of the surrounding fluid because of shear. The impinging jet in cryogenic-assisted machining process is in liquid phase at the nozzle exit. The state of impinging jet on injection is, however, at pressure and temperature, both at the subcritical state. Width of the impinging jet is very small when the ratio between the jet pressure and the critical pressure is around 0.03 . Under such conditions, the impinging jet has appearance that of liquid ligaments and the ejection takes place in the form of drops $[40,41]$. The heat transfer rate is enhanced with the dissolution of the gas in the impinging jet. The enhanced heat transfer rate is observed prominently in the sub-cooled boiling region [42].

The diameter of the jet is approximately ten times the diameter of the injector. This depends on the length of dense core and temperature of the impinging jet. The cooling capacity of the jet is maximum in the liquid jet core region and therefore the tool insert surface that has temperature lower to that of core region receives the major advantage of cooling from the impinging jet. Classical liquid breakup theory decides the behaviour of the impinging jet in conditions that are highly sub critical [52]. It is estimated that by the time the nitrogen gas reaches the target, it is around 50\%in liquid phase given the fact that the hot material workpiece surface is at distance approximately 35 times the diameter of the impinging jet. The ensuing result is fluid expansion that has a positive effect on the chip clearance. This becomes beneficial for applications limiting the employability of forced air [43].

Baron and Stanely [44] have investigated the mechanism of film boiling occurring with the impinging cryogenic jet. They established the relationship for the average coefficient of heat transfer for jet impinging on a circular plate. The relationship between average Nusselt number, Prandtl number and the Reynold number was established. These were in turn revealed to be dependent on the nozzle exit diameter, thermal properties, physical properties and mass flow of the impinging jet.

Heat transfer mechanism in the cryogenic-assisted machining process has been investigated by Dreister [45]. The investigation was carried out for nozzles with different ranges of diameters, temperatures of target surface and flow velocities. It was observed that depending on the inclination angle of the surface and the average jet velocity, a layer of liquid boundary layer is formed over a zone that is approximately fivefold the diameter of the impinging jet. The coefficient of heat transfer was also found to be forty notch higher in comparison with that for natural convection.
Investigations on transient behaviour of impinging jet have been carried out by researchers $[46,47]$. It was observed that the impinging jet has contact for a very short duration of time with the workpiece material. Further, a higher surface cooling rate of up to $8^{\circ} \mathrm{C} / \mathrm{ms}$ was also reported. Also the surface coefficient of heat transfer was revealed to be very small at the separation point between the tool and the chip [47].

The value of surface coefficient heat transfer was reported to reach the order of $10^{4} \mathrm{w} / \mathrm{m}^{2} \mathrm{k}$ in the open region cloud. Flow analysis for multiphase flow was carried out for the liquefied nitrogen gas [48]. Flow rate was maintained at $1 \mathrm{~L} / \mathrm{min}$, nozzle diameter was kept at $2 \mathrm{~mm}$, and the distance from the target surface was maintained at $15 \mathrm{~mm}$ during the CFD analysis. The cooling rate was estimated to be $2{ }^{\circ} \mathrm{C} / \mathrm{ms}$ at the intersecting point of the axis of the impinging jet with that of the workpiece material. The coefficient of heat transfer at the same point was revealed to be of the order of $10^{4} \mathrm{w} / \mathrm{m}^{2} \mathrm{k}$. This decreases along the wall of the impinging jet. The rate of decrease was reported to be $600 \mathrm{w} / \mathrm{m}^{2} \mathrm{k} / \mathrm{mm}$.

Zhang et al. [49] investigated the behaviour of liquefied nitrogen gas jet being confined in a larger tube. The investigations were carried out for different surfaces of heat transfer under varied conditions. Rigorous disturbances were reported on to the heat transfer surfaces owing to the strong exchange of fluid momentum. The momentum exchange occurs when the flow fluid reverses its direction in the confined domain and that too in a very short duration of time. The flow penetrates into the boiling region with the gradual increase in the temperature of the hot surface. This is the point where the critical heat flux is approached. Further, I was reported that with the increasing jet velocity of liquefied nitrogen gas, the capability of heat transfer as well the critical heat flux increases. In the confined region, the convective evaporation process dictates the nucleate boiling mechanism.

However, the complexity is further increased with the presence of wedged opening [50]. The dominant behaviour of the conducting heat in the narrow gap was attributed to the reason for added complexity.

To judge the effectiveness of a cutting fluid, it is quintessential to quantify the heat transfer taking place between the cryogenic cutting fluid and the cutting tool and also between the cutting tool and the surface being machined. There are various modes of heat transfer mechanisms, the common being conduction, radiation and convection. However, the researchers have focussed primarily on the convection mechanism of heat transfer mechanism [51]. Cryogenic fluid in liquid phase has higher dynamic viscosity and specific heat in comparison with the gas and therefore has more heat transfer capability $[52,53]$. However, a vapor cushion is formed owing to the evaporation of 
the liquid cryogenic fluid [54]. The vapor film restricts the heat transfer potentiality of the cryogenic fluid [55]. The boundary film can, however, be eliminated keeping in vey some of the critical parameters such as the exit velocity at the nozzle and also the pressure of the liquid cryogenic fluid [56]. Further, the orientation and positioning of the nozzle also effects the tool-wear $[11,30]$. The modeling of the heat transfer process at the cutting zone is difficult as at the exit of the nozzle, there may be either liquid, gas or mix of two. Monitoring of cryogenic fluid has been carried by Pusavec et al. [57] by employing a phase sensor.

The quantification of the heat transfer mechanism is quite difficult using a direct approach. Therefore, inverse methodology has been often used by the researchers for determination of the heat transfer coefficient. This is done by comparison of the cutting temperatures obtained numerically and experimentally. Heat transfer coefficient as high as $50,000 \mathrm{w} / \mathrm{m}^{2} \mathrm{k}$ was reported by Rotella and Umbrello [58] when machining AA7075-T651 alloy. A value of $20,000 \mathrm{w} / \mathrm{m}^{2} \mathrm{k}$ for machining of Ti-6Al4V was reported by Rotella and Umbrello [59]. The value was reported for cases of cryogenic cooling. A value of $20 \mathrm{w} / \mathrm{m}^{2} \mathrm{k}$ was reported for free convection condition while machining Ti-6Al4V. Coefficient of heat transfer with value approximately $2000 \mathrm{w} / \mathrm{m}^{2} \mathrm{k}$ was reported for machining under dry compressed air [60].

There is, however, requirement to assess the literatures on forced convection boiling mainly with the sole objective to enhance the heat transfer process in cryogenicassisted machining processes. Increased coefficient of heat transfer was reported by providing coating of a material possessing low thermal conductivity to the surface to be cooled [45]. Various alternatives to the liquefied nitrogen have been used for cooling purposes in various applications. However, their applicability for cryogenic machining process still needs to be explored. Usage of nitrogen in gas phase and combination of air with liquefied nitrogen gas could be explored for machining processes. In case of latter, the liquid particles possess greater inertia as gained from the air streamlines and results in the formation of a thin liquid film around the stagnation point [48]. Single and multiple impinging jets with turbulent conditions have resulted to provide significant heat transfer enhancement [61-63].

\section{Cryogenic machining of PDMS}

Machining of elastomers has one of the problems of providing suitable fixtures. Investigations and advent of cryogenic machining has aided in fixing the aforementioned problem. Further, it has also become possible to keep them lower than the glass transition temperature. An array of reports have been published on this aspects by varied researchers [64-67]. The condition to machine below the glass transition temperature is required so as to prevent the polymeric material to convert into rigid state. Under this condition of workpiece temperature, cutting forces can be applied and thereby justifying the feasibility of $\mathrm{CNC}$ machining. Specially designed fixture was employed by Kakinuma et al. [65] for carrying out cryogenic machining of polydimethylsiloxane (PDMS). It was reported that the machinability of PDMS was enhanced with the employability of cryogenic machining. However, geometrical inaccuracies were also reported within the workpiece material.

Cryogenic cooling was also employed for the milling operation [67]. Three nozzles were employed around the milling tool that aided in effective cooling of the workpiece material in all the directions. A noteworthy improvement in the workpiece material surface integrity was reported with the assistance of cryogenic cooling. Furthermore, a better chip flow characteristics as well as reduced workpiece deformation was obtained with the process. The cryogenicassisted milling process was revealed to machine elastomeric structures with thickness as low as $0.5 \mathrm{~mm}$.

One of the major applications of cryogenics in polymeric machining is that of freezing of the raw material. This in turn leads to effective machinability of the polymeric material. The effectiveness in machinability is achieved with the change of material state of polymeric material from being ductile to brittle. The transformation takes place at the glass transition temperature. Enhanced ductility as well as elongation is achieved for the polymeric material with the assistance of cryogenics. The improved properties aids the polymeric material to withstand the machining forces without much deformation.

Milling of ethylene-vinyl acetate to obtain shoe soles was successfully achieved by Dhokia et al. [67]. The milling process was done in assistance with the cryogenics, i.e., with the employability of liquefied nitrogen gas. The cryogenicassisted milling process was put forth as an alternative to injection moulding which otherwise is expensive as well as time consuming. Kakinuma et al. [65] have designed and developed a fixture to freeze PDMS materials. This has been done for the microfluidic application. The micro-fluidic chips are manufactured generally by micro-moulding process or by photolithography. With the aid of cryogenics in freezing the workpiece material and in machining, micro-milling has been used for the production of micro-fluidic chips. 


\section{Cryogenic machining of Inconel and stainless steel}

The cost associated with the flow rates of liquefied nitrogen and carbon dioxide gas was estimated by Pusavec et al. [68] and Klocke et al. [69]. The estimation of cost for carbon dioxide was done for five different nozzle, while only single nozzle was considered for liquefied nitrogen gas. The real cost of the process can be accessed by combining consumption of cooling lubrication with the productivity of tool life. Lower machining costs have been reported for cryogenic machining of Inconel 718 material [70]. Conventional machining is economical only at lower speeds of cutting which is, however, not optimal from production rate point of view. Therefore, for higher rate of production and higher efficiency, cryogenic-assisted machining must be opted over conventional machining.

Further investigations have been carried out and comparison has been made between cryogenic machining with high pressure liquefied nitrogen gas and the conventional machining with oil emulsions [71, 72]. A case of Austenitic stainless steel workpiece material was investigated under the study. It was reported that the tool life was enhanced by $100 \%$ for the case of cryogenics employing liquefied nitrogen gas. The tooling costs reported was much higher for conventional machining than the cryogenic-assisted machining. A direct relationship between the flow rate and the machining performance with the cost for the cryogenic machining was reported by Lu [47].

Further, the cost associated with cryogenic machining in terms of total life-cycle cost is justified with the enhanced functional performance of the manufactured components obtained using cryogenic associated machining processes.

\section{Sustainability issues associated with cryogenic-assisted machining}

Meeting the requirements of customer through the production of goods, systems and services is the primary reason of existence of machining processes. The term "sustainability" on the other hand can be explained as "meeting the needs of the present without jeopardizing the ability of future generations to meet their needs" [73]. As such in accordance to the Department of Commerce, USA, sustainable machining can be defined as the "creation of manufactured products through the processes that are non-polluting, energy conservative and nature conservative and also economically sound and safe for employees".
The sustainability in machining has been adopted through the utilization of efficient resources, recyclable materials, reusing of machine-tools, minimization of waste, minimization of energy consumption, enhancement in tool life, expanding the managerial scope for the usage of metalworking fluids, lubricating oils, and adoption of life cycle assessment methods [74]. Cryogenic machining is a machining approach that complies with the three vital pillars of any sustainable machining: environmental, societal, and economic [75].

Employability of conventional coolants in machining processes results into numerous problems as such environmental pollution, biological problems, soil contamination, water pollution, and additional infrarequirements in the form of floor space and machining equipment [76]. The disposal of conventional coolants after their usage is limited by environmental laws and hence adds to the sustainability issues. Cryogens on the other hand are safe and evaporates after their usage and therefore leaves no residue. Also, cryogenic machining is economic as the cost is low to machine parts in comparison with the processes without cryogens. Some of the elements that make up the total cost of cryogenic machining are machining costs, cutting fluid cost, electrical cost, cleaning cost associated with the final part, cost associated with recycling and cost of cleaning the chips and other residual matter [77]. Sustainability in societal terms is also provided by the cryogenic machining which include labor rights, operational safety, personal health, and labor justice [77].

A case study on comparison of sustainability performance for the cryogenic machining and conventional flood cooling was conducted by Lu et al. [78]. The factors that were considered for the study were cost, productivity, energy consumption were evaluated. The case for which the study was made concerned the milling of Ti-6Al-4V blank that was employed for the fabrication of frame structure. Cryogenic machining process was able to machine at twice the rate in comparison with the conventional flood cooling process and therefore the same machining plant can produce twice the capacity without making investment on its infrastructure. The cryogenic machining consumed $22.8 \%$ lesser power in comparison with the conventional flood cooling process. The greenhouse gas emitted were almost 50\% lesser for the cryogenic-assisted machining. Furthermore no liquid waste was generated by the cryogenic machining process because of the evaporation of $L N$ into air that leaves no residue. There was a total cost reduction of $26 \%$ for machining of one piece of part using cryogenic-assisted machining process. Therefore through the case study, the potential benefits of the machining process in terms of economic and sustainability aspect was justified. 


\section{Technical and economic aspects of cryogenic-assisted machining}

The cryogenic-assisted machining process has proved to be successful in removing the heat and therefore accelerating the chip fragmentation process. This in turn results into overall improvement in the tool life of the employed tools. The employability of liquid nitrogen is wider due to its potential ability to rapidly evaporate from the cutting zone. The rapid evaporation aids in hampering the tool softening process. Moreover, the evaporation of liquid nitrogen readily into the atmosphere and hence reduces the friction as well as the post-process cleaning operations [79]. The effect of the effect of cryogenic cooling onto the heat generation was simulated by Dinesh et al. [80] for different cutting speed levels. 15-20\% lower temperature was achieved in temperature in comparison with the temperature generated during dry machining. Cryogenic machining has reported to enhance the machinability of hardened steels [81], titanium [82] and Inconel [83]. The positive effect of cryogenic-assisted machining was reported on the high-temperature alloys by Kaynak [84]. The effects were studied on the cutting temperature, crater wear, flank wear and the quality of the machined surface. The tool life of the tool was compared for the conventional and cryogenic-assisted machining processes [85]. At lower depth of cut, the machining processes with conventional cooling showed higher tool life. However, higher depth of cut was achievable with the cryogenicassisted machining process with the same tool life.

There has been, however, an enormous lacuna to investigate the cost reduction with industrial outlook. It is the cost of the fluid that plays a crucial role in the cryogenicassisted machining processes. The cost of fluid is supposed to vary the total machining cost from 15 to $17 \%$ [20]. The other prominent cost that the machining encounters is that associated with the tooling cost. The tool wear plays a prominent role in deciding the cost of machining titanium alloys [86]. Another major proportion of the machining cost is associated with the energy consumption of the machine that is being employed to carry out machining process [87]. 39\% less machining cost has been reported in a study related with cryogenic-assisted machining [88].

\section{Conclusion}

The present work is a modest attempt to provide the readers with the different characteristics of the cryogenic-assisted machining process that has emerged as one of the most suitable sustainable processes. Thermal and economic aspects of the cryogenics-assisted machining process have been highlighted in the present work. Different findings as reported in the present work depicts the efficacy of cryogenics to aid in production of products that are far more superior in their functionality. Further, the cost effectiveness of the process over the conventional machining process has been revealed in the discussion on economic aspect. Cryogenics have made it easy the machining of polymeric materials. However, modeling of such processes is still a complex problem that remains to be suitably addressed by the research community working in this domain. Further, development of performance predictive models is still an area that provides for future research directions to the scientific community.

In the near future the possibility of cryogenic machining to be integrated with the non-conventional machining [89] needs to be reviewed. Moreover, the reviews must be made with regard to the integration with Industry 4.0 considering the behaviour of different materials $[90,91]$. The micromachining processes may also be extended to incorporate cryogenics [92].

\section{Compliance with ethical standards}

Conflict of interest The authors declare that they have no competing interests.

\section{References}

1. Abele E, Schramm B (2008) Using PCD for machining CGI with a $\mathrm{CO}_{2}$ coolant system. Prod Eng Res Devel 2(2):165

2. De Chiffre L, Andreasen JL, Lagerberg S, Thesken IB (2007) Performance testing of cryogenic $\mathrm{CO}_{2}$ as cutting fluid in parting/ grooving and threading austenitic stainless steel. CIRP Ann Mach Technol 56(1):101-104

3. Dix M, Wertheim R, Schmidt G, Hochmuth C (2014) Modeling of drilling assisted by cryogenic cooling for higher efficiency. CIRP Ann Mach Technol 63(1):73-76

4. Machai C, Biermann D (2011) Machining of $\beta$-titanium-alloy Ti-10V-2Fe-3Al under cryogenic conditions: cooling with carbon dioxide snow. J Mater Process Technol 211(6):1175-1183

5. Tsai HH, Hocheng H (1998) Investigation of the transient thermal deflection and stresses of the workpiece in surface grinding with the application of a cryogenic magnetic chuck. J Mater Process Technol 79(1-3):177-184

6. Yalçın B, Özgür AE, Koru M (2009) The effects of various cooling strategies on surface roughness and tool wear during soft materials milling. Mater Des 30(3):896-899

7. Reitz G (1919) Die Grosse des geistlichen und ritterschaftlichen Grundbesitzes im ehemaligen Kur-Trier. Rheinische FriedrichWilhelms-Universitat zu Bonn

8. ASHRAE Handbook-Fundamentals (2010) American Society of Heating Refrigerating and Air-Conditioning Engineers Inc, Atlanta Georgia, USA 
9. Uehara K, Kumagai S (1968) Chip formation, surface roughness and cutting force in cryogenic machining. Ann CIRP 17(1):409-416

10. Dillon OW, De Angelis RJ, Lu WY, Gunasekera JS, Deno JA (1990) The effects of temperature on the machining of metals. J Mater Shap Technol 8(1):23-29

11. Hong SY, Ding Y (2001) Cooling approaches and cutting temperatures in cryogenic machining of Ti-6Al-4V. Int J Mach Tools Manuf 41(10):1417-1437

12. Hong SY, Zhao Z (1999) Thermal aspects, material considerations and cooling strategies in cryogenic machining. Clean Prod Process 1(2):107-116

13. Byers JP (2017) Metalworking fluids. CRC Press, Boca Raton

14. Cassin C, Boothroyd G (1965) Lubricating action of cutting fluids. J Mech Eng Sci 7(1):67-81

15. De Chiffre $L$ (1988) Function of cutting fluids in machining. Lubr Eng 44:514-518

16. El Baradie MA (1996) Cutting fluids: Part I. Characterisation. J Mater Process Technol 56(1-4):786-797

17. Hong SY (2006) Lubrication mechanisms of $\mathrm{LN}_{2}$ in ecological cryogenic machining. Mach Sci Technol 10(1):133-155

18. Shaw MC (1959) On the action of metal cutting fluids at low speeds. Wear 2(3):217-227

19. Adler DP, Hii WS, Michalek DJ, Sutherland JW (2006) Examining the role of cutting fluids in machining and efforts to address associated environmental/health concerns. Mach Sci Technol 10(1):23-58

20. Shokrani A, Dhokia V, Newman ST (2012) Environmentally conscious machining of difficult-to-machine materials with regard to cutting fluids. Int J Mach Tools Manuf 57:83-101

21. Shokrani Chaharsooghi A, Dhokia V, Newman S (2014) A techno-health study of the use of cutting fluids and future alternatives. In: 24th international conference on flexible automation and intelligent machining (FAIM 2014). University of Bath

22. Byrne G, Dornfeld D, Denkena B (2003) Advancing cutting technology. CIRP Ann Mach Technol 52(2):483-507

23. Klocke FA, Eisenblätter G (1997) Dry cutting. CIRP Ann 46(2):519-526

24. Weinert K, Inasaki I, Sutherland JW, Wakabayashi T (2004) Dry machining and minimum quantity lubrication. CIRP Ann Mach Technol 53(2):511-537

25. Clapp RW, Jacobs MM, Loechler EL (2008) Environmental and occupational causes of cancer: new evidence 2005-2007. Rev Environ Health 23(1):1-38

26. de Joode BV, Bierman EP, Brouwer DH, Spithoven J, Kromhout $H$ (2005) An assessment of dermal exposure to semi-synthetic metal working fluids by different methods to group workers for an epidemiological study on dermatitis. Occup Environ Med 62(9):633-641

27. Hong SY (1999) Inventor; Edison Materials Tech Center, assignee. Cryogenic machining. United States patent US $5,901,623$

28. Hong SY, Ding Y, Jeong J (2002) Experimental evaluation of friction coefficient and liquid nitrogen lubrication effect in cryogenic machining. Mach Sci Technol 6(2):235-250

29. Malloy EJ, Miller KL, Eisen EA (2007) Rectal cancer and exposure to metalworking fluids in the automobile machining industry. Occup Environ Med 64(4):244-249

30. Shokrani A, Dhokia V, Muñoz-Escalona P, Newman ST (2013) State-of-the-art cryogenic machining and processing. Int J Comput Integr Mach 26(7):616-648

31. Jayal AD, Badurdeen F, Dillon OW Jr, Jawahir IS (2010) Sustainable machining: modeling and optimization challenges at the product, process and system levels. CIRP J Mach Sci Technol 2(3):144-152
32. Kaynak Y, Lu T, Jawahir IS (2014) Cryogenic machining-induced surface integrity: a review and comparison with dry, MQL, and flood-cooled machining. Mach Sci Technol 18(2):149-198

33. Pu Z, Outeiro JC, Batista AC, Dillon OW Jr, Puleo DA, Jawahir IS (2012) Enhanced surface integrity of AZ31B Mg alloy by cryogenic machining towards improved functional performance of machined components. Int J Mach Tools Manuf 56:17-27

34. Pu Z, Song GL, Yang S, Outeiro JC, Dillon OW Jr, Puleo DA, Jawahir IS (2012) Grain refined and basal textured surface produced by burnishing for improved corrosion performance of AZ31B Mg alloy. Corros Sci 57:192-201

35. Umbrello D, Micari F, Jawahir IS (2012) The effects of cryogenic cooling on surface integrity in hard machining: a comparison with dry machining. CIRP Ann Mach Technol 61(1):103-106

36. Yang S, Umbrello D, Dillon OW Jr, Puleo DA, Jawahir IS (2015) Cryogenic cooling effect on surface and subsurface microstructural modifications in burnishing of $\mathrm{Co}-\mathrm{Cr}-\mathrm{Mo}$ biomaterial. $\mathrm{J}$ Mater Process Technol 217:211-221

37. Astakhov VP (2009) Metal cutting theory foundations of neardry (MQL) machining. Int J Mach Mach Mater 7(1-2):1-6

38. Sharma VS, Dogra M, Suri NM (2009) Cooling Techniques for Improved Productivity in Turning. Int J Mach Tools Manuf 49:435-453

39. Barron RF (1982) Cryogenic treatment of metals to improve wear resistance. Cryogenics 22(8):409-413

40. Chehroudi B, Talley D, Coy E (2002) Visual characteristics and initial growth rates of round cryogenic jets at subcritical and supercritical pressures. Phys Fluids 14(2):850-861

41. Chehroudi B, Talley D, Mayer W, Branam R, Smith JJ (2003) Understanding injection into high pressure supercritical environments. Air Force Research Lab Edwards AFB CA Propulsion Directorate

42. Woodcraft AL (2007) An introduction to cryogenics. SUPA Institute of Astronomy. Edinburgh University, Blakford Hill

43. Zelinski $P(2011)$ The $400^{\circ}$ difference-cryogenic machining achieves dramatic tool life gains not by flooding the cut, but by refrigerating the tool. Modern Machine Shop 83(10):66

44. Barron RF, Stanley RS (1994) Film boiling under an impinging cryogenic jet. In: Advances in cryogenic engineering. Springer, Boston, pp 1769-1777

45. Dreitser GA (2003) Modern problems of cryogenic heat transfer and its enhancement (generalization of experimental results, practical recommendations and different applications). In: Low temperature and cryogenic refrigeration. Springer, Dordrecht, pp 201-220

46. Haustein HD, Tebrügge G, Rohlfs W, Kneer R (2012) Local heat transfer coefficient measurement through a visibly-transparent heater under JetImpinge Cooling. Int J Heat Mass Transf 55:6410-6424

47. Lu T (2014) A metrics-based sustainability assessment of cryogenic machining using modeling and optimization of processperformance, Theses and Dissertations-Mechanical Engineering. 47, University of Kentucky.

48. Elsayed A, Attia MH, Damir A (2016) Computer fluid dynamics analysis for enhanced cooling of cutting tools in turning operation. In: Internal report, structures, materials and machining laboratory

49. Zhang P, Xu GH, Fu X, Li CR (2011) Confined jet impingement of liquid nitrogen onto different heat transfer surfaces. Cryogenics 51(6):300-308

50. Attia MH, D'Silva N (1984) Thermal analysis of the fuel bearing pad in the CANDU reactor-prediction of nucleate boiling. In: Multi-Phase flow and heat transfer III. Part B: applications

51. Klocke F, Krämer A, Sangermann H, Lung D (2012) Thermomechanical tool load during high performance cutting of hardto-cut materials. Procedia CIRP 1:295-300 
52. Courbon C, Pusavec F, Dumont F, Rech J, Kopac J (2013) Tribological behaviour of Ti6AI4V and Inconel718 under dry and cryogenic conditions-application to the context of machining with carbide tools. Tribol Int 66:72-82

53. Pusavec F, Courbon C, Rech J, Kopac J, Jawahir IS (2015) An investigation of the effect of nitrogen phase on cryogenic machining performance and a case study on machining of Inconel 718 alloy. In: 2014 International machining science and engineering conference collocated with the JSME 2014 international conference on materials and processing and the 42nd North American machining research conference 2014 Jun 9 . American Society of Mechanical Engineers, pp V002T02A055-V002T02A055

54. Dhokia V, Shokrani Chaharsooghi A, Newman S (2012) Cryogenic machining of carbon fibre. In: 12th International conference of the European society for precision engineering and nanotechnology 2012. University of Bath

55. Bermingham MJ, Palanisamy S, Kent D, Dargusch MS (2012) A comparison of cryogenic and high pressure emulsion cooling technologies on tool life and chip morphology in Ti-6Al-4V cutting. J Mater Process Technol 212(4):752-765

56. Qi SL, Zhang P, Wang RZ, Xu LX (2007) Flow boiling of liquid nitrogen in micro-tubes: Part II-Heat transfer characteristics and critical heat flux. Int J Heat Mass Transf 50(25-26):5017-5030

57. Pusavec F, Lu T, Courbon C, Rech J, Aljancic U, Kopac J, Jawahir IS (2016) Analysis of the influence of nitrogen phase and surface heat transfer coefficient on cryogenic machining performance. J Mater Process Technol 233:19-28

58. Rotella G, Umbrello D (2014) Numerical simulation of surface modification in dry and cryogenic machining of AA7075 alloy. Procedia CIRP 13:327-332

59. Rotella G, Umbrello D (2014) Finite element modeling of microstructural changes in dry and cryogenic cutting of Ti6Al4V alloy. CIRP Ann Mach Technol 63(1):69-72

60. Sun S, Brandt M, Dargusch MS (2010) Machining Ti-6Al-4V alloy with cryogenic compressed air cooling. Int J Mach Tools Manuf 50(11):933-942

61. Chorowski M. Combined thermo-hydraulic analysis of a cryogenic jet. In: Advances in cryogenic engineering 2000. Springer, Boston, pp 1189-1196

62. Tesař V (2009) Enhancing impinging jet heat or mass transfer by fluidically generated flow pulsation. Chem Eng Res Des 87(2):181-192

63. Xu P, Yu B, Qiu S, Poh HJ, Mujumdar AS (2010) Turbulent impinging jet heat transfer enhancement due to intermittent pulsation. Int J Therm Sci 49(7):1247-1252

64. Mishima K, Kakinuma Y, Aoyama T (2010) Pre-deformationassisted cryogenic micromachining for fabrication of threedimensional unique micro channels. J Adv Mech Des Syst Mach 4(5):936-947

65. Kakinuma Y, Yasuda N, Aoyama T (2008) Micromachining of soft polymer material applying cryogenic cooling. J Adv Mech Des Syst Mach 2(4):560-569

66. Kakinuma Y, Kidani S, Aoyama T (2012) Ultra-precision cryogenic machining of viscoelastic polymers. CIRP Ann Mach Technol 61(1):79-82

67. Dhokia VG, Newman ST, Crabtree P, Ansell MP (2010) A methodology for the determination of foamed polymer contraction rates as a result of cryogenic CNC machining. Robot Comput Integr Mach 26(6):665-670

68. Pusavec F, Krajnik P, Kopac J (2010) Transitioning to sustainable production-Part I: application on machining technologies. J Clean Prod 18(2):174-184

69. Klocke F, Lung D, Krämer A, Cayli T, Sangermann H (2013) Potential of modern lubricoolant strategies on cutting performance. In: Key engineering materials, vol 554. Trans Tech Publications, pp 2062-2071
70. Pušavec F, Stoić A, Kopač J (2010) Sustainable machining process-myth or reality. Strojarstvo 52(2):197-204

71. Kramer A (2014) Gestaltungsmodell der kryogenen Prozessku "hlung in derZerspanung (in German). Ph.D. Dissertation, WZL RWTH Aachen

72. Jawahir IS, Attia H, Biermann D, Duflou J, Klocke F, Meyer D, Newman ST et al (2016) Cryogenic machining processes. CIRP Ann 65(2):713-736

73. Brundtland G, Khalid M, Agnelli S, Al-Athel S, Chidzero B, Fadika $L$, Hauff $V$ et al (1987) Report of the world commission on environment and development "our common future". In: Annex to UN general assembly document A/42/427. United Nations, New York

74. Benedicto E, Carou D, Rubio EM (2017) Technical, economic and environmental review of the lubrication/cooling systems used in machining processes. Procedia Eng 184:99-116

75. Sutherland JW, Richter JS, Hutchins MJ, Dornfeld D, Dzombak $\mathrm{R}$, Mangold J, Robinson S et al (2016) The role of machining in affecting the social dimension of sustainability. CIRP Ann 65(2):689-712

76. Yousfi M, Outeiro JC, Nouveau C, Marcon B, Zouhair B (2017) Tribological behavior of PVD hard coated cutting tools under cryogenic cooling conditions. Procedia CIRP 58:561-565

77. Dhar NR, Paul S, Chattopadhyay AB (2002) Machining of AISI 4140 steel under cryogenic cooling - tool wear, surface roughness and dimensional deviation. J Mater Process Technol 123(3):483-489

78. Lu T, Kudaravalli R, Georgiou G (2018) Cryogenic machining through the spindle and tool for improved machining process performance and sustainability: Pt. I, system design. Procedia Mach 21:266-272

79. Josyula SK, Narala SKR (2018) Performance enhancement of cryogenic machining and its effect on tool wear during turning of Al-Ticp composites. Mach Sci Technol 22(2):225-248

80. Dinesh S, Senthilkumar V, Asokan P, Arulkirubakaran D (2015) Effect of cryogenic cooling on machinability and surface quality of bio-degradable ZK60 Mg alloy. Mater Des 87:1030-1036

81. Kim DM, Kim DY, Jo IS, Song TJ, Paik KS, Park HW (2017) Experimental tool wear observation of assisted high pressure cryogenic jet in hard turning process. In: ASME 2017 12th international manufacturing science and engineering conference collocated with the JSME/ASME 2017 6th international conference on materials and processing. American Society of Mechanical Engineers Digital Collection

82. Krishnamurthy G, Bhowmick S, Altenhof W, Alpas AT (2017) Increasing efficiency of Ti-alloy machining by cryogenic cooling and using ethanol in MRF. CIRP J Manuf Sci Technol 18:159-172

83. Pusavec F, Hamdi H, Kopac J, Jawahir IS (2011) Surface integrity in cryogenic machining of nickel based alloy-Inconel 718. J Mater Process Technol 211(4):773-783

84. Kaynak Y (2014) Evaluation of machining performance in cryogenic machining of Inconel 718 and comparison with dry and MQL machining. Int J Adv Manuf Technol 72(5-8):919-933

85. Sharma VS, Dogra M, Suri NM (2009) Cooling techniques for improved productivity in turning. Int J Mach Tools Manuf 49(6):435-453

86. Hegab HA, Darras B, Kishawy HA (2018) Towards sustainability assessment of machining processes. J Clean Prod 170:694-703

87. Hubbard KM, Callahan RN, Strong SD (2008) A standardized model for the evaluation of machining coolant/lubricant costs. Int J Adv Manuf Technol 36(1-2):1-10

88. Conradie P, Dimitrov D, Oosthuizen G (2016) A cost modelling approach for milling titanium alloys. Procedía CIRP 46(1):412-415

89. Faisal N, Zindani D, Kumar K, Bhowmik S (2019) Laser micromachining of engineering materials-a review. In: Micro and 
nano machining of engineering materials. Springer, Cham, pp $121-136$

90. Kumar K, Zindani D, Paulo Davim J (2019) Industry 4.0: developments towards the fourth industrial revolution. Springer, Berlin

91. Kumar K, Kalita H, Zindani D, Paulo Davim J (2019) Mechanical behaviour of materials. In: Materials and manufacturing processes. Springer, Cham, pp 21-34

92. Kumar K, Zindani D, Kumari N, Paulo Davim J (eds) (2018) Micro and nano machining of engineering materials: recent developments. Springer, Berlin
Publisher's Note Springer Nature remains neutral with regard to jurisdictional claims in published maps and institutional affiliations. 